\title{
ANALYSIS OF MATTERS AFFECTING LAND PRICE FLUCTUATIONS IN THE GREAT EAST JAPAN EARTHQUAKE
}

\author{
Takato Azegami ${ }^{1}$, Akira Takahashi², Kensuke Yasufuku², Noriko Otsuka ${ }^{3}$, Tomoko Miyagawa ${ }^{4}$ and \\ *Hirokazu Abe ${ }^{2}$ \\ ${ }^{1}$ Takenaka Corporation, Japan; ${ }^{2}$ Osaka University, Japan; ${ }^{3}$ ILS Research Institute for Regional and Urban \\ Development, Germany; ${ }^{4}$ Wakayama University, Japan
}

*Corresponding Author, Received: 06 Oct. 2021, Revised: 01 Dec. 2021, Accepted: 09 Jan. 2022

\begin{abstract}
Using a hedonic regression approach, this research aims to identify what factors affected land price fluctuations in Fukushima Prefecture following the Great East Japan Earthquake and the Fukushima Daiichi Nuclear Power Station accident in 2011. In this paper, taking a long-term perspective, the analysis focuses on Iwaki City in Fukushima, where the real estate market behaved unexpectedly following the two catastrophic events, and land price fluctuation rates were rising abnormally. Results based on analysis of data for eight-year indicate the following: The impact of radiation air dose rate and distance from the nuclear power plant on land price fluctuation rate changed significantly from the fourth year after the disaster. Being located in a reconstruction base area had a negative impact on land price fluctuation rate, while access to sewers and city gas had a positive impact. It appears that the stigma associated with the accident had a little disappeared after approximately four years.
\end{abstract}

Keywords: Land price, Hedonic Approach, Great East Japan Earthquake, Nuclear Accident

\section{INTRODUCTION}

Ten years have passed since the Great East Japan Earthquake. At this point, many of the countermeasures of the reconstruction/creation period have been completed [1]. The reconstruction of housing in the disaster area has progressed significantly. In Fukushima prefecture, 4890 restoration public housing units and 694 disaster public housing units for returnees have been completed. The supply of public housing has almost reached the initial target [2]. However, it has been not only the damage caused by the earthquake and tsunami but also the radioactive contamination resulting from the Fukushima Daiichi Nuclear Power Plant accident that has had long-term effects on the physical, psychological, and social wellbeing of the victims. This was a completely different case from past earthquakes in Japan, and unprecedented measures have been required. Given the severity of the radioactive contamination, it was impossible to respond immediately to the problems and anxieties of the residents, and many victims were forced to evacuate the area, seeking a new living base either within or outside the prefecture. In 2017, at last, the evacuation orders issued to 12 municipalities in Fukushima prefecture had been lifted except for the difficult-to-return areas of Namie, Futaba, and Okuma, where the annual cumulative air dose exceeds $50 \mathrm{mSv} /$ year [3].

Fukushima Prefecture's land prices were also radically affected by the radioactive contamination. In 2012, immediately after the earthquake, land prices in all residential and commercial areas in Fukushima Prefecture fell significantly. In 2013, land prices at all points in the commercial area continued to decrease. However, two years after the earthquake, the official land prices in Iwaki City showed an abnormal rate of increase, not only for Fukushima Prefecture but for all of Japan. This had a substantial impact on the housing supply available to victims. The radioactive contamination and the subsequent evacuation orders resulting from the nuclear accident were unique events in the world. Accordingly, attempting to understand the large fluctuations in land prices that occurred in the disaster area is a significant part of understanding the massive effects of this unprecedented catastrophe.

The purpose of this paper is to identify those factors that influenced post-disaster land price fluctuations in Iwaki City, where land prices rose abnormally following the Great East Japan Earthquake and the Fukushima Daiichi Nuclear Power Station accident.

Previous research related to earthquake disasters and land price fluctuations includes a study by Nomura et al. [4], which analyzed the impact of the Great Hanshin Earthquake in 1995 on land prices using a hedonic approach. It was found that in 1996, the year immediately following the earthquake, the decrease in land prices was directly proportional to the degree of damage to buildings (i.e., the greater the damage to buildings, the lower the land price). However, in 1997, land prices stopped falling in areas where buildings had been destroyed or burned 
to the ground, while in areas with high halfdestruction rates, land prices continued to fall. While Kawawaki [5] examines the influence of consumer's risk perception on land prices in the disaster area of the Hanshin Earthquake before and after the earthquake, it suggests that the land price fell by information of the earthquake risk.

Regarding the relationship between land price fluctuations after the earthquake and real estate sales in Fukushima Prefecture, Kawamura [6] pointed out that the spatial movement and settlement of many victims was a significant factor. Mori [7] assessed real estate circulation circumstances before and after the earthquake in Iwaki city. Saito [8] analyzed the impact of accepting evacuees from the nuclear accident on city planning in Iwaki City, focusing on changes in population and land use. He found that houses were scattered on a small scale and built-in places that were not intended to be residential areas, pointing to the need to develop a new living environment after such a disaster. Yamahashi [9] examined the actual urban form of municipalities along the coast and its problem after the Great East Japan Earthquake by focusing on the spatial distribution of development permission. Consequently, it revealed that the individual housing developments in urbanization control areas are generally restrained compared to the development pressure.

These studies focused on factors such as the number of real estate transactions in the disaster area, the rate of increase in land prices, and changes in land use. Few studies are discussing the relationship between land prices and the stigma of radioactive contamination caused by a nuclear accident. Hirota [10] considered the outlook for the real estate market in the year of the Great East Japan Earthquake, highlighting concerns about the decline in real estate value and the associated stigma with soil pollution from diffused radioactivity. As an overseas reference example, he also introduced a research report by Gambling and Downing [11] describing the impact on land prices of the Three Mile Island accident in the United States.

\section{METHOD}

As noted, the purpose of this paper is to identify how the Great East Japan Earthquake and the Fukushima Daiichi Nuclear Power Station accident affected the real estate market in the region. Focusing on fluctuations in land prices in Iwaki City, the study quantitatively analyzes the effects of various social factors caused by the earthquake from a long-term perspective using a hedonic regression approach. We first investigate changes in land price fluctuation rate and changes in the air dose (radiation dose of the surrounding environment emitted from radioactive materials) throughout Fukushima Prefecture following the disaster and describe the position of Iwaki City within the prefecture. Next, we create a land price volatility function using multivariate analysis based on the official land prices in Iwaki City. We then establish how various factors associated with the earthquake affected the land price fluctuation rate in the disaster area.

\section{POST-EARTHQUAKE LAND PRICES AND AIR DOSES IN FUKUSHIMA}

\subsection{Land Prices After the Earthquake}

Figure 1 shows the fluctuation of land prices in seven cities and towns (Fukushima City, Koriyama City, Shirakawa City, Aizu-Wakamatsu City, Minami-Aizu Town, Minami-soma City, Iwaki City), represented by seven regions of Fukushima Prefecture. The land price used here is the average of the official land price and benchmark land price. The official land price is the land price announced on January 1st every year based on an appraisal by two or more real estate appraisers for each plot set by the Ministry of Land, Infrastructure, Transport and Tourism (MLIT). The benchmark land price is the land price determined by the prefecture on July 1st every year based on an appraisal by one or more real estate appraisers per plot. Compared to the previous year, the land price fluctuations rate were negative until 2011 and then turned positive in all regions except Minami-Aizu in 2013 after the earthquake.

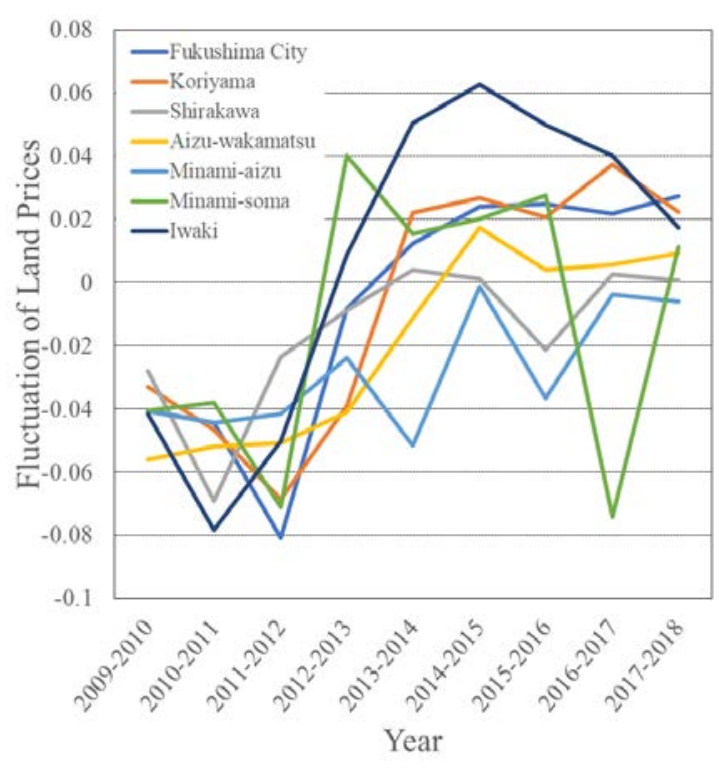

Fig.1 Fluctuation of land prices in seven areas of Fukushima Prefecture. 
However, the movements show different patterns in each region. The fluctuation in land prices in Minami-soma and Iwaki changed significantly after the earthquake, and the fluctuation in Iwaki rose abnormally from 2013 to 2016 compared to other regions. Possible reasons for this are the acceptance of approximately 24,000 evacuees in the Futaba District and the transfer of workers who worked at the nuclear power plant while accommodated in Iwaki city during the countermeasure process. (Approximately 10\% of the population of Iwaki City) However, this is not sufficient to explain the complex relationship between the earthquake and nuclear plant disaster and land price fluctuations.

On the other hand, unlike other areas, Minamisoma, where many victims were forced to evacuate due to the nuclear accident, experienced rapid changes in land price fluctuations. There were no major changes in land price fluctuations in AizuWakamatsu, Minami-Aizu, and Shirakawa.

\subsection{Air Dose Rate After the Earthquake}

Figure 2 shows the changes in the air dose rate from 2011 to 2018 in the seven representative cities of the regions of Fukushima Prefecture. We used the air dose rates $(\mu \mathrm{Sv} / \mathrm{h})$ for the seven representative cities that were listed on the website of the Fukushima Reconstruction Station. (Measured location is the government building in each city, the prefectural north health and welfare office building in Fukushima city) On this site, the air dose rate measurement results in Fukushima Prefecture are recorded by measuring the air dose every hour in each area. Here, the average of the measurement results at 00:00 on the first day of each month of the year is taken as the air dose rate for the year.

Since the radioactive materials diffused by the Fukushima Daiichi Nuclear Power Plant accident flowed towards the west by the wind, the values in Fukushima City and Koriyama City, which are located west of the nuclear power plant, are quite high, at more than $1.0 \mu \mathrm{Sv} / \mathrm{h}$. Especially in 2011, Shirakawa City, Minami-soma City, and Iwaki City had air dose rates exceeding $0.23 \mu \mathrm{Sv} / \mathrm{h}$. The Ministry of the Environment has determined that the requirement for an area to be included in the decontamination implementation plan is an area with an air dose rate of $0.23 \mu \mathrm{Sv} / \mathrm{h}$ or more. This value is calculated by converting the additional exposure dose of $1 \mathrm{mSv} / \mathrm{y}$ into the radiation dose per hour and adding the natural radiation dose.

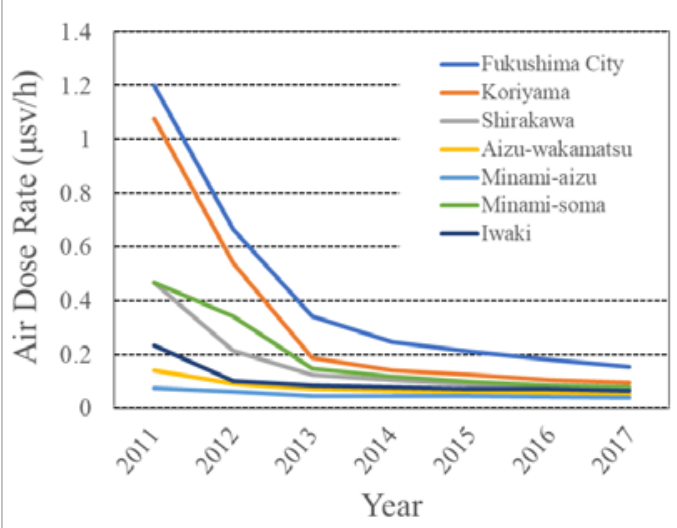

Fig. 2 Changes in air dose rate in seven areas of Fukushima Prefecture.

Table 1 Correlation coefficients of land price fluctuations and air dose rates in seven cities from $2011-2018$

\begin{tabular}{|c|c||c|c|}
\hline Region & $\begin{array}{c}\text { Correlation } \\
\text { coefficient }\end{array}$ & Year & $\begin{array}{c}\text { Correlation } \\
\text { coefficient }\end{array}$ \\
\hline Fukushima City & -0.99 & 2011 & -0.66 \\
\hline Koriyama & -0.97 & 2012 & 0.04 \\
\hline Shirakawa & -0.65 & 2013 & 0.34 \\
\hline Aizu-Wakamatsu & -0.90 & 2014 & 0.11 \\
\hline Minami-Aizu & -0.48 & 2015 & 0.38 \\
\hline Minami-Soma & -0.27 & 2016 & 0.20 \\
\hline Iwaki & -0.89 & 2017 & 0.80 \\
\hline
\end{tabular}

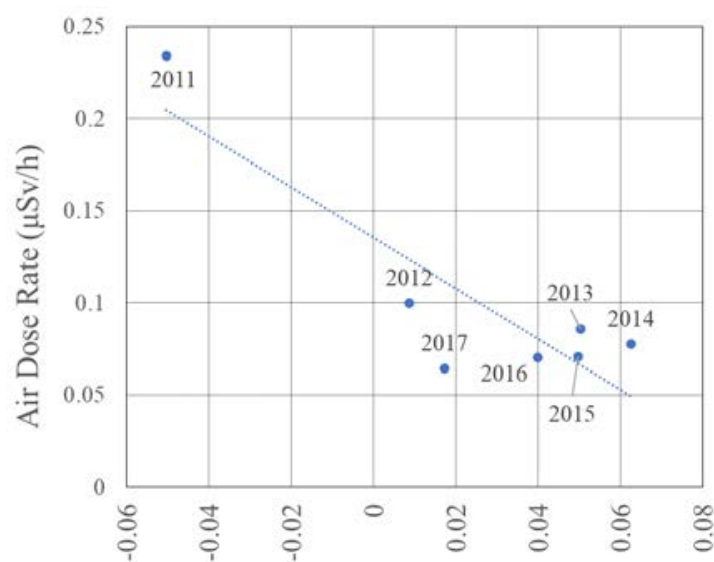

Land Price Fluctuations

Fig.3 Scatter plot of air dose rates and land price fluctuations in Iwaki City

Since 2013, the air dose rate in all seven regions has decreased due to decontamination work and 
attenuation, and in 2017, the air dose rate at the monitoring posts in the seven areas was below 0.23 $\mu \mathrm{Sv} / \mathrm{h}$.

Table 1 shows the correlation coefficients indicating the degree of correlation between land price fluctuations and air dose rates in the seven representative cities in seven regions of Fukushima Prefecture from 2011 to 2017. Figure 3 shows a scatter plot of the air dose rates and land price fluctuations in Iwaki city.

Regarding each region in Table 1 , it shows a very high (negative) correlation between land price fluctuation and air dose in Fukushima, Koriyama, Iwaki, and Aizu. On the other hand, in MinamiAizu, Shirakawa, and Minami-soma, where the air dose was relatively low, the correlation between the land price fluctuation and the air dose tended to be low. However, regarding the high correlation coefficient of Aizu, it is possible that unfounded stigma occurred due to the relatively large population. There is almost no correlation between the yearly correlation coefficients in Table 1 except for 2011 and 2017. Since the initial air doses are different in each city of Fukushima, it is considered that there was a limit to the analysis of them collectively for each year.

\section{LAND PRICE FLUCTUATIONS AFTER THE EARTHQUAKE IN IWAKI CITY}

It is believed that the rise in land prices in Iwaki City after the earthquake is mainly due to the acceptance of evacuees and the presence of workers at the nuclear plant. We analyzed the situation using the hedonic approach to quantitatively determine what factors affected the land price fluctuations in Iwaki City.

\subsection{Analytical Method (Hedonic Approach)}

The hedonic method is a regression technique used to estimate the prices of qualities or models that are not available on the market in particular periods but whose prices in those periods are needed to be able to construct price relatives [12]. Because the hedonic approach is based on the capitalization hypothesis, in this paper, we consider that land prices are determined by a variety of factors, including the surrounding environment, and express them as vectors for characteristics that contribute to land price [13]. Multiple regression analysis is used to implement this approach. In this study EXCEL multivariate analysis Ver.6.0, Esumi Co., Ltd. was used.

\subsection{Setting Surveyed Sites}

The surveyed sites in this paper are the standard land of the official land price set by MLIT (103 sites) and the standard land of benchmark land price set by the local government (77 sites), for a total of 180 sites in Iwaki City (2018).

\subsection{Objective Variables and Explanatory Variables}

The objective variable in the hedonic approach used in this paper is the land price fluctuation (rate of land price in a given year compared to the previous year) at each surveyed site in the analysis. The explanatory variables are the various environmental factors that potentially affected the real estate market during the period from the earthquake to the reconstruction of the study site in the following criteria.

1) building and infrastructure related variables;

Land area, floor area ratio, front road condition, Lifeline (city-gas or sewer), distance from the nearest station, distance to Iwaki station, along national or prefectural road, site shape, building structure, building usage status (a total of 24 items)

2) built environment-related variables;

Surroundings and surveyed site surroundings (a total of 24 items)

3) different districts;

Taira district, Onahama district, Nakoso district, Joban district, Uchigo district, Yotsukura district, Tono district, Ogawa district, Yoshima district, Sanwa district, Taito district, Kawamae district, Kunohama/Oku district (a total of 13 items, all of which are converted to dummy variables)

4) variables directly related to the nuclear power plant;

Air does, distance to the nuclear power plant, tsunami inundation area, and reconstruction base area (a total of 4 items)

A total of 55 explanatory variables have been set.

\subsection{Examination of Each Explanatory Variable and Multicollinearity}

Among the explanatory variables above, there may be multicollinearity that could adversely affect the estimation accuracy of the model. To ensure that the hedonic function produces a highly explanatory model, the presence or absence of multicollinearity is established using a correlation coefficient table. If the value of VIF (Variance Inflation Factor) calculated after the multivariate analysis is greater than 10 , then the presence or absence of the effect of that variable is re-examined. 
Table 2 shows the final set of explanatory variables after excluding factors that were causing the multicollinearity. Concerning the quantitative variables shown in the table, since 12 stations besides Iwaki Station were used well, we chose to omit "distance to Iwaki station" (DS) as an explanatory variable.

Table 2 Explanatory variables

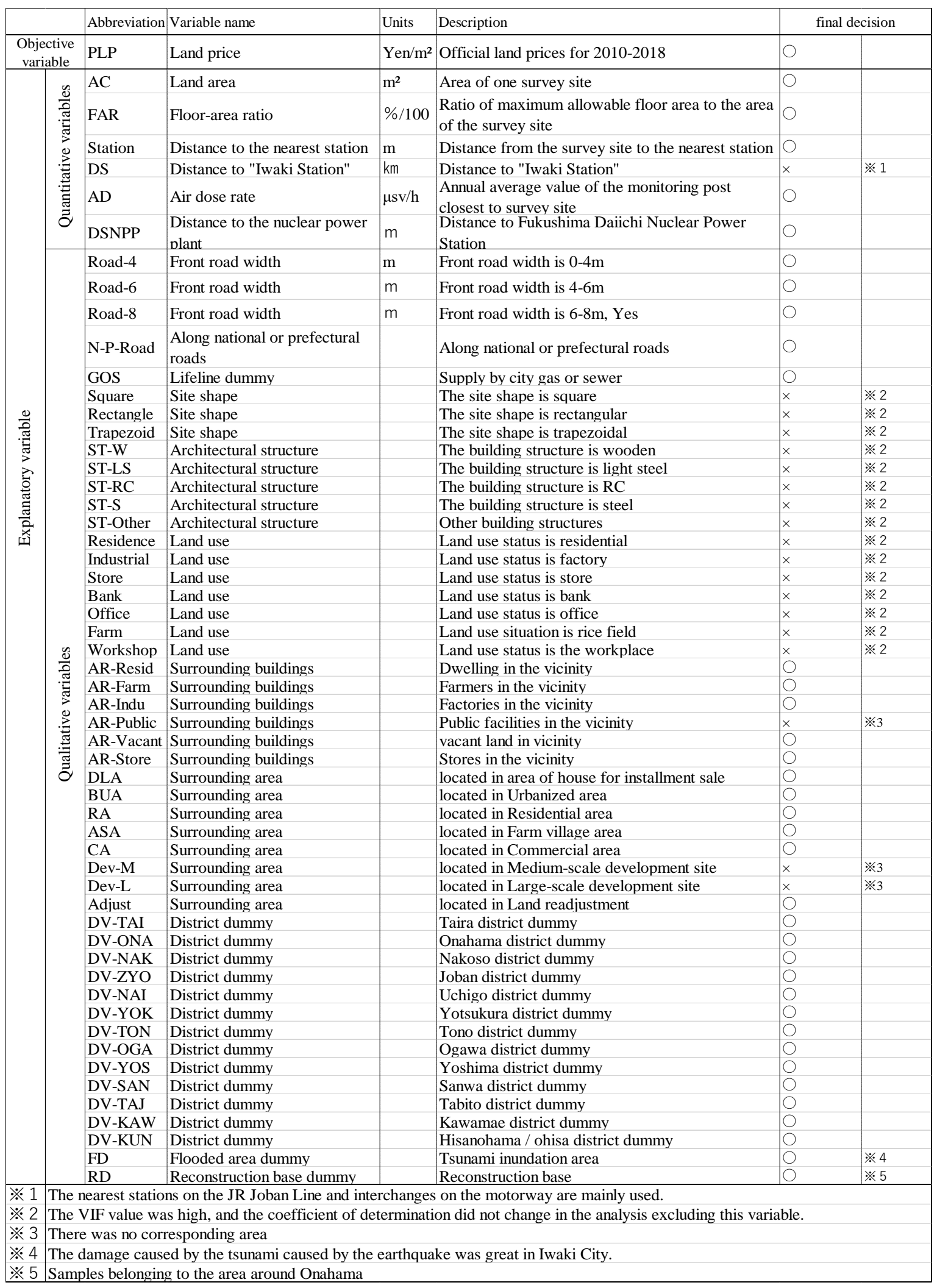


Regarding air dose (AD), since the values at each survey site were not measured, we applied the air dose values at the monitoring post closest to the site. The monitoring post uses the Fukushima Prefecture Radioactivity Measurement Map operated by Fukushima Prefecture. When the closest monitoring post changes, it is changed every year. (For the measured values of air dose rate ( $\mu$ $\mathrm{Sv} / \mathrm{h}$ ) at the monitoring post, the Fukushima Prefecture website is referred.)

Among the qualitative variables shown in the table, the front road width (Road-4,6,8) at the survey site includes widths of 0 to $4 \mathrm{~m}, 4$ to $6 \mathrm{~m}$, and 6 to $8 \mathrm{~m}$. Dummy variables are set for each range.

Table 3 Correlation coefficients for explanatory variables

\begin{tabular}{|c|c|c|c|c|c|c|c|}
\hline & & PLP & AC & FAR & Station & $A D$ & DSNPP \\
\hline 2011 & \begin{tabular}{|l|} 
PLP \\
AC \\
FAR \\
Station \\
AD \\
DSNPP \\
\end{tabular} & $\begin{array}{r}1.00 \\
0.04 \\
0.00 \\
-0.17 \\
0.06 \\
-0.29 \\
\end{array}$ & $\begin{array}{r}1.00 \\
0.00 \\
0.00 \\
-0.05 \\
0.07 \\
\end{array}$ & $\begin{array}{r}1.00 \\
-0.32 \\
-0.18 \\
0.01 \\
\end{array}$ & $\begin{array}{l}1.00 \\
0.03 \\
0.08 \\
\end{array}$ & $\begin{array}{r}1.00 \\
-0.53 \\
\end{array}$ & 1.00 \\
\hline 2012 & $\begin{array}{l}\text { PLP } \\
\text { AC } \\
\text { FAR } \\
\text { Station } \\
\text { AD } \\
\text { DSNPP }\end{array}$ & $\begin{array}{r}1.00 \\
-0.02 \\
-0.17 \\
0.11 \\
0.18 \\
-0.14\end{array}$ & $\begin{array}{r}1.00 \\
0.00 \\
0.00 \\
-0.01 \\
0.07\end{array}$ & $\begin{array}{r}1.00 \\
-0.32 \\
-0.22 \\
0.01\end{array}$ & $\begin{array}{l}1.00 \\
0.01 \\
0.08\end{array}$ & $\begin{array}{r}1.00 \\
-0.63\end{array}$ & 1.00 \\
\hline 2013 & \begin{tabular}{|l} 
PLP \\
AC \\
FAR \\
Station \\
AD \\
DSNPP \\
\end{tabular} & $\begin{array}{r}1.00 \\
-0.10 \\
-0.27 \\
-0.05 \\
0.11 \\
-0.14 \\
\end{array}$ & $\begin{array}{r}1.00 \\
0.00 \\
0.00 \\
-0.04 \\
0.07 \\
\end{array}$ & $\begin{array}{r}1.00 \\
-0.32 \\
-0.01 \\
0.01 \\
\end{array}$ & $\begin{array}{l}1.00 \\
0.05 \\
0.08\end{array}$ & $\begin{array}{r}1.00 \\
-0.39 \\
\end{array}$ & 1.00 \\
\hline 2014 & \begin{tabular}{|l} 
PLP \\
AC \\
FAR \\
Station \\
AD \\
DSNPP \\
\end{tabular} & $\begin{array}{r}1.00 \\
-0.10 \\
-0.23 \\
-0.10 \\
0.09 \\
-0.04 \\
\end{array}$ & $\begin{array}{r}1.00 \\
0.00 \\
0.00 \\
-0.04 \\
0.07 \\
\end{array}$ & $\begin{array}{r}1.00 \\
-0.32 \\
0.06 \\
0.01 \\
\end{array}$ & $\begin{array}{r}1.00 \\
-0.07 \\
0.08 \\
\end{array}$ & $\begin{array}{r}1.00 \\
-0.41 \\
\end{array}$ & 1.00 \\
\hline 2015 & $\begin{array}{l}\text { PLP } \\
\text { AC } \\
\text { FAR } \\
\text { Station } \\
\text { AD } \\
\text { DSNPP }\end{array}$ & $\begin{array}{r}.07 \\
-0.11 \\
-0.29 \\
-0.09 \\
-0.05 \\
0.01\end{array}$ & $\begin{array}{r}1.00 \\
0.00 \\
0.00 \\
-0.03 \\
0.07\end{array}$ & $\begin{array}{r}1.00 \\
-0.32 \\
0.05 \\
0.01\end{array}$ & $\begin{array}{r}1.00 \\
-0.04 \\
0.08\end{array}$ & $\begin{array}{r}1.00 \\
-0.48\end{array}$ & 1.00 \\
\hline 2016 & \begin{tabular}{|l} 
PLP \\
AC \\
FAR \\
Station \\
AD \\
DSNPP \\
\end{tabular} & $\begin{array}{r}1.00 \\
-0.11 \\
-0.27 \\
-0.07 \\
-0.10 \\
-0.06 \\
\end{array}$ & $\begin{array}{r}1.00 \\
0.00 \\
0.00 \\
-0.03 \\
0.07\end{array}$ & $\begin{array}{r}1.00 \\
-0.32 \\
0.08 \\
0.01 \\
\end{array}$ & $\begin{array}{r}1.00 \\
-0.05 \\
0.08 \\
\end{array}$ & $\begin{array}{r}1.00 \\
-0.42 \\
\end{array}$ & 1.00 \\
\hline 2017 & \begin{tabular}{|l} 
PLP \\
AC \\
FAR \\
Station \\
AD \\
DSNPP \\
\end{tabular} & $\begin{array}{r}1.00 \\
-0.11 \\
-0.24 \\
-0.07 \\
-0.07 \\
-0.12\end{array}$ & $\begin{array}{r}1.00 \\
0.00 \\
0.00 \\
-0.02 \\
0.07\end{array}$ & $\begin{array}{r}1.00 \\
-0.32 \\
0.09 \\
0.01\end{array}$ & $\begin{array}{r}1.00 \\
-0.10 \\
0.08\end{array}$ & $\begin{array}{r}1.00 \\
-0.48\end{array}$ & 1.00 \\
\hline 2018 & $\begin{array}{l}\text { PLP } \\
\text { AC } \\
\text { FAR } \\
\text { Station } \\
\text { AD } \\
\text { DSNPP }\end{array}$ & $\begin{array}{r}-0.12 \\
-0.00 \\
-0.06 \\
-0.08 \\
-0.09 \\
-0.02\end{array}$ & $\begin{array}{r}1.00 \\
0.00 \\
0.00 \\
-0.03 \\
0.07\end{array}$ & $\begin{array}{r}1.00 \\
-0.32 \\
0.08 \\
0.01\end{array}$ & $\begin{array}{r}1.00 \\
-0.07 \\
0.08\end{array}$ & $\begin{array}{r}1.00 \\
-0.47\end{array}$ & 1.00 \\
\hline
\end{tabular}

As for site shape (Square, Rectangle, Trapezoid), building structure (ST-W, LS, RC, S, Other), and land use (Residence, Industrial, Store, Bank, Office, Farm, Workshop), the VIF value at the time of the analysis greatly exceeded 10 . Moreover, when these variables were excluded, the coefficient of determination and the $\mathrm{p}$-value value was significant.
Consequently, these factors were excluded from the set of explanatory variables.

The list of explanatory variables related to surrounding buildings initially included ARResidence (houses around the survey site), ARFarm (farmhouses around the survey site), ARIndustrial (factories around the survey site), ARPublic (public facilities around the survey site), ARVacant (vacant lot around the survey site), and ARStore (when there is a store around the survey site). However, since no survey sites were corresponding to AR-Public, AR-Public was excluded from the final set of explanatory variables.

Similarly, the initial list of explanatory variables related to the surrounding area included LA (survey site is located in an area of houses for installment sale), BUA (site is in an urbanized area), RA (site is in a residential area), ASA (site is in a farm village area), CA (site is in a commercial area), Dev-M (site is in a medium-sized development area), Dev-L (site is in a large-scale development site), and Adjust (a land readjustment is involved). However, since no survey sites were corresponding to Dev-M and Dev-L, these two variables were excluded from the final set of explanatory variables.

The inundation area dummy (FD) indicates that the survey site is within the tsunami inundation area according to data on the 2011 Great East Japan Earthquake released by the Geospatial Information Authority of Japan. The reconstruction base dummy (RD) refers to being located in the Onahama hinterland tsunami reconstruction base development project in the reconstruction plan of Iwaki City. Table 3 shows the correlation coefficients among the quantitative explanatory variables. For the explanatory variables, there were no significantly high correlation coefficients ( $\mathrm{r}>=$ 0.8).

\section{RESULTS AND DISCUSSION}

\subsection{Coefficient of Determination and Model Validity}

Table 4 shows the coefficients of determination, adjusted coefficients of determination, and sample sizes from 2011 to 2018. For 2011 and 2012, the coefficients of determination $\left(\mathrm{R}^{2}\right)$ were 0.33 and 0.22 respectively, and adjusted values (Adjusted $R^{2}$ ) were 0.06 and -0.07 , indicating a poor goodness-offit for the model.

This would appear to be largely due to the rapid decrease in land price in Iwaki City immediately after the earthquake. The various environmental factors that determine the normal land price fluctuation rate may not have responded clearly to the turmoil of the land market during this period. On 
the other hand, from 2013, the land price fluctuation rate shows an upward trend, and the coefficients of determination for the model are all above 0.5. The adjusted coefficients of determination are also substantially higher. Thus, the model's explanatory power, as reflected in its better goodness-of-fit, appears to be much stronger. Consequently, it is considered an effective means for estimating land price fluctuations after 2013.

Table 4 Coefficients of determination (2011-2018)

\begin{tabular}{|c|c|c|c|}
\hline & $\begin{array}{l}\text { Coefficient } \\
\text { determination }\left(\mathrm{R}^{2}\right)\end{array}$ & Adjusted $\mathrm{R}^{2}$ & $\begin{array}{l}\text { Number of } \\
\text { samples }\end{array}$ \\
\hline 2011 & 0.334 & 0.062 & 125 \\
\hline 2012 & 0.225 & -0.063 & 134 \\
\hline 2013 & 0.562 & 0.403 & 136 \\
\hline 2014 & 0.598 & 0.468 & 148 \\
\hline 2015 & 0.713 & 0.630 & 161 \\
\hline 2016 & 0.726 & 0.647 & 163 \\
\hline 2017 & 0.658 & 0.567 & 171 \\
\hline 2018 & 0.525 & 0.402 & 176 \\
\hline
\end{tabular}

\subsection{Multiple Regression Analysis}

Table 5 shows the standardized partial regression coefficients and significance levels from 2011 to 2018. No significant results were produced for the land area (AC) variable during the estimation period. It suggests that the size of the land area did not affect the land price fluctuation during the reconstruction period.

On the other hand, the effect of the floor area ratio (FAR) was found to be negative and significant at the $1 \%-5 \%$ level from 2013 to 2017, thus suggesting that the floor area ratio hurt the land price. This would seem to run counter to what would normally be expected. Since, in general, a larger floor area ratio means that a larger floor area can be constructed, the floor area ratio is typically a variable that contributes positively to a rise in land price fluctuation rate; however, here, it appears to work oppositely. This result is thought to be due to the high demand for low- and middle-rise housing in Iwaki City during this time.

Distance from the nearest station (Station) was shown to have a significant negative effect (at the 10\% significance level) in 2015, 2017, and 2018. This result indicates that the shorter the distance from the nearest station, the greater the land price fluctuation is.

Air dose (AD) was not significant until 2014. However, it had a significant negative effect (at the 1\%-10\% level) between 2015 and 2018, suggesting that this environmental factor negatively impacted the land price fluctuation rate. Moreover, since the standardized partial regression coefficient for air dose is rather large, it can be inferred that its influence on the land price fluctuation rate was substantial. The likely reason for this is that the excessive demand for housing had begun to settle down, and air dose considerations came to constitute a large portion of the judgment factors affecting the residents' choice of a place to live.

A significant positive effect (at the $5 \%$ level) was found for distance from the Fukushima Daiichi Nuclear Power Station in 2013; however, a significant negative effect (at the $10 \%$ level) was found for this same variable in 2017 and 2018.

In 2013, the larger the distance from the Fukushima Daiichi Nuclear Power Station, the higher was the land price fluctuation. In contrast, in 2017 and 2018, the larger the distance to the Fukushima Daiichi Nuclear Power Station, the lower the land price fluctuation was. Immediately following the earthquake, evacuees were concerned about the unknown dangers of the nuclear power plant and generally looked for a place to live that was far from the Fukushima facility. However, several years after the earthquake, many became less anxious or less concerned about the dangers. It appears that the stigma associated with the accident had a little disappeared after approximately four years.

There is great variation among the district dummies (DV-TAI, ONA, NAK, ZYO, NAI, YOK, TON, OGA, YOS, SAN, TAJ, KAW, KU). In 2015 and 2016, a significant positive effect (at the 5\%$10 \%$ level) was found in the Taira and Onahama areas. These areas are among the most reconstructed areas in Iwaki City. This was also the time when many disaster-related public housing and group relocation promotion projects were completed.

A significant negative effect (at the $1 \%-5 \%$ level) can be seen in 2011 for areas in the northern part of Iwaki City, such as the Yotsukura, Hisanohama, and Kawamae districts; however, the coefficient of determination is quite small from 2011 to 2012, making it difficult to evaluate based on the model. In 2017 and 2018, a significant negative effect (at the 1\%-10\% level) was found in most areas, except the Onahama area. As the reconstruction progressed and the demand for housing slowed down, it seems that the land market fell to the level that was seen in the local cities before the earthquake.

For the flooded area dummy (FD), no significant results were produced until 2016; thereafter, a significant positive effect (at the 5\%-10\% level) was found in 2017 and 2018. The positive impact of the tsunami inundation variable since 2017 may be due to the progress of the tsunami countermeasures, such as seawalls.

The Reconstruction Base Area dummy (RD) was a significant negative effect (at the $5 \%$ level) in 2013, 2015, and 2016. Despite the business vision, the land price fluctuation rate fell near the Onahama Table 5 Standardized partial regression coefficients (2011-2018) 


\begin{tabular}{|c|c|c|c|c|c|c|c|c|c|}
\hline \multirow{2}{*}{\multicolumn{2}{|c|}{$\frac{\text { Explanatory variable }}{\text { logprice }}$}} & \multicolumn{8}{|l|}{ Coef. } \\
\hline & & 2011 & 2012 & 2013 & 2014 & 2015 & 2016 & 2017 & 2018 \\
\hline \multirow{5}{*}{ 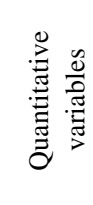 } & AC & 0.123 & -0.032 & -0.031 & -0.060 & -0.053 & -0.052 & -0.046 & -0.030 \\
\hline & FAR & -0.020 & -0.070 & -0.320 & -0.237 & -0.235 & -0.201 & -0.220 & -0.020 \\
\hline & Station & 0.033 & 0.164 & 0.015 & -0.022 & -0.140 & -0.067 & -0.134 & -0.158 \\
\hline & $\mathrm{AD}$ & 0.720 & -0.148 & -0.042 & 0.024 & -0.163 & -0.203 & -0.191 & -0.156 \\
\hline & DSNPP & 0.159 & 0.177 & 0.778 & 0.287 & -0.151 & -0.203 & -0.695 & -0.557 \\
\hline \multirow{31}{*}{ 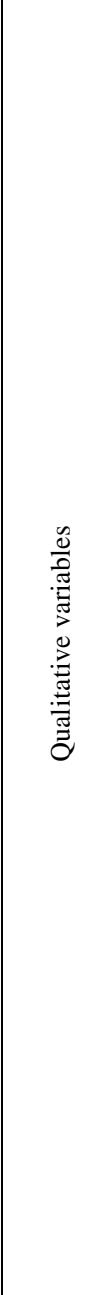 } & DV-TAI & -0.342 & 0.211 & 0.525 & 0.300 & 0.414 & 0.232 & -0.036 & -0.276 \\
\hline & DV-ONA & -0.155 & -0.027 & 0.050 & 0.165 & 0.452 & 0.349 & 0.323 & 0.083 \\
\hline & DV-NAK & -0.252 & -0.047 & -0.558 & -0.183 & 0.159 & 0.044 & 0.180 & -0.065 \\
\hline & DV-ZYO & -0.160 & 0.040 & 0.026 & -0.054 & 0.035 & -0.002 & -0.042 & -0.216 \\
\hline & DV-NAI & -0.310 & 0.176 & 0.123 & -0.023 & 0.036 & -0.077 & -0.130 & -0.228 \\
\hline & DV-YOK & -0.571 & 0.036 & 0.082 & -0.019 & -0.003 & 0.131 & -0.140 & -0.364 \\
\hline & DV-TON & -0.363 & 0.022 & -0.210 & -0.201 & -0.107 & -0.155 & -0.135 & -0.139 \\
\hline & DV-OGA & -0.024 & 0.133 & 0.147 & 0.046 & -0.001 & -0.064 & -0.188 & -0.200 \\
\hline & DV-YOS & -0.208 & 0.085 & 0.250 & 0.090 & 0.092 & 0.041 & -0.084 & -0.221 \\
\hline & DV-SAN & -0.451 & 0.037 & 0.009 & 0.037 & 0.067 & 0.007 & -0.038 & -0.019 \\
\hline & DV-TAJ & -0.457 & 0.066 & -0.204 & -0.171 & -0.019 & -0.085 & -0.053 & -0.115 \\
\hline & DV-KAW & -0.128 & 0.101 & 0.078 & -0.096 & -0.184 & -0.186 & -0.289 & -0.307 \\
\hline & DV-KUN & -0.595 & 0.264 & 0.185 & 0.008 & -0.085 & -0.136 & -0.262 & -0.306 \\
\hline & FD & -0.127 & 0.033 & -0.095 & -0.085 & 0.063 & 0.062 & 0.113 & 0.161 \\
\hline & $\mathrm{RD}$ & 0.124 & -0.171 & -0.206 & -0.093 & -0.175 & -0.163 & -0.114 & -0.089 \\
\hline & Road-4 & -0.009 & -0.222 & 0.001 & 0.021 & 0.209 & 0.341 & 0.300 & 0.195 \\
\hline & Road-6 & -0.258 & -0.423 & 0.333 & 0.403 & 0.597 & 0.863 & 0.800 & 0.599 \\
\hline & Road-8 & -0.287 & -0.192 & 0.416 & 0.381 & 0.340 & 0.653 & 0.663 & 0.488 \\
\hline & GOS & 0.043 & 0.095 & 0.334 & 0.310 & 0.226 & 0.281 & 0.176 & 0.161 \\
\hline & N-P-Road & 0.088 & -0.050 & -0.124 & -0.174 & -0.114 & -0.080 & -0.106 & -0.027 \\
\hline & AR-Resid & 0.192 & 0.035 & 0.014 & 0.072 & 0.014 & 0.040 & 0.058 & -0.016 \\
\hline & AR-Farm & 0.117 & -0.043 & -0.034 & -0.138 & -0.112 & -0.148 & -0.274 & -0.241 \\
\hline & AR-Indu & -0.021 & 0.103 & 0.078 & 0.041 & 0.043 & 0.046 & 0.065 & 0.133 \\
\hline & AR-Vacant & -0.057 & -0.210 & -0.159 & -0.110 & -0.009 & -0.065 & -0.100 & -0.056 \\
\hline & AR-Store & -0.116 & -0.174 & -0.037 & 0.018 & -0.043 & 0.018 & 0.042 & 0.123 \\
\hline & DLA & 0.016 & -0.073 & -0.058 & -0.083 & -0.003 & 0.038 & 0.036 & 0.142 \\
\hline & BUA & -0.163 & -0.068 & 0.023 & -0.001 & 0.071 & 0.027 & 0.133 & 0.172 \\
\hline & RA & -0.213 & 0.184 & 0.242 & 0.315 & 0.295 & 0.256 & 0.331 & 0.483 \\
\hline & ASA & 0.046 & 0.135 & -0.007 & -0.032 & -0.121 & -0.063 & -0.027 & -0.055 \\
\hline & CA & 0.036 & 0.179 & 0.073 & 0.044 & 0.062 & -0.044 & 0.010 & -0.067 \\
\hline & Adjust & -0.027 & -0.093 & 0.004 & 0.046 & 0.050 & 0.057 & 0.064 & -0.005 \\
\hline \multicolumn{2}{|c|}{ Land price volatility rise } & $10 \%$ level & 5\%level & $1 \%$ level & \multicolumn{2}{|c|}{$\begin{array}{l}\text { Land price volatility } \\
\text { decline }\end{array}$} & $10 \%$ level & 5\%level & $1 \%$ level \\
\hline
\end{tabular}

Port tsunami reconstruction center development project.

The influence of front road width (Road-4,6,8) was found to be positive and significant (at the 1\%$5 \%$ level) in 2015, 2016, and 2017. A sufficiently wide front road is advantageous in terms of access to parking lots and daylighting conditions and thus seems to be preferred as a condition for choosing a residence. For the lifeline dummies (GOS), a significant positive effect (at the $1 \%$ level) was found from 2013 to 2018. The construction of sewers and city gas lines is a very important factor in the rapid reconstruction of living space after a disaster, and has a great positive impact on land price fluctuations.

Among the surrounding buildings variables (AR-Residence, Industrial, Store, Bank, Office, Farm, Workshop), the effect of AR-Farm was negative and significant (at the 1\%-5\% level) between 2016 and 2018, and the effect of the ARVacant was negative and significant (at the $10 \%$ level) in 2013. This suggests that the land price fluctuation rate will decrease if there are farms or vacant lots around the survey area.

Finally, regarding the area around the surveyed 
site (DLA, BUA, RA, ASA, CA, Dev-L, Dev-M, Adjustment), DLA (house for installment sale area) had a significant positive effect (at the $5 \%$ level) in 2018. BUA (urbanized area) had a significant positive effect (at the 5\%-10\% level) in 2016/2017, and RA (residential area) had a significant positive effect (at the 1\%-5\% level) from 2014 through 2018. After the disaster, it seems that Iwaki City experienced an increase in demand by evacuees seeking a place of residence.

\section{CONCLUSION}

Focusing on Iwaki City, where the real estate market behaved unexpectedly after the Great East Japan Earthquake, and land price fluctuation rates were rising abnormally, this paper used a hedonic regression approach to identify those factors that significantly affected area land price fluctuations. The results are as follows:

1. From 2013 to 2016, when an abnormal rise in land price fluctuation rates was observed, the explanatory variables having a significant positive effect were the Taira and Onahama area dummies, Front road width, Lifeline, and Surrounding area.

2. Regarding distance from the Fukushima Daiichi Nuclear Power Station, it was found that in 2013, the larger the distance, the higher the land price fluctuation rate was. In contrast, in 2017 and 2018, the larger the distance, the lower the land price fluctuation rate was.

3. Regarding reconstruction bases (RD), land price fluctuation rates decreased in all such areas. As for the impact of lifelines (GOS), a significant positive effect was found between 2013 and 2018.

4. Air dose (AD) was not significant until 2014. However, it had a significant negative effect (at the 1\%-10\% level) between 2015 and 2018, suggesting that this environmental factor negatively impacted the land price fluctuation rate.

The effect of the air dose and distance from the nuclear power plant variables changed significantly after the 4th year since the earthquake. On the other hand, regardless of the time of year, a negative impact on land price fluctuation rate was shown for the reconstruction base variable, while a positive impact was shown for lifelines. It suggests that the stigma for land that existed after the accident was a little resolved in roughly four years.

We have issues to be addressed in the future. Since the coefficient of determination $\left(\mathrm{R}^{2}\right)$ in 2011 and 2012 was rather small, the model for Iwaki City was ill-fitting for 2011 and 2012. We intend to improve the explanatory power of the hedonic model by adding surveyed sites and explanatory variables that reflect the regional characteristics of the survey area, the rate of collapse of houses, and the rate of population decline.

\section{ACKNOWLEDGMENTS}

We are grateful for a Grant-in-Aid for Scientific Research (18K18602) for supporting this research.

\section{REFERENCES}

[1] Great East Japan Earthquake 10th Anniversary Online Symposium, Reconstruction Agency, https://www.reconstruction.go.jp/10year/en/, (November $6^{\text {th }}, 2021$ )

[2] Disaster Redevelopment Field, Urban Renaissance Agency https://www.ur-net.go.jp/profile/English/pdf/ profile_en_11.pdf (November $6^{\text {th }}$, 2021)

[3] Fukushima Revitalization Station, Fukushima Prefectural Government https://www.pref.fukushima.lg.jp/site/portalenglish/list385.html (November 6th, 2021)

[4] Nomura K., Ohara M., and Meguro K., Analysis of Change of Land Price After an Urban Earthquake -Case Study in Affected Area Due to The 1995 Kobe Earthquake-, Journal of Japan Society of Civil Engineers A1 Vol.65, No.1, p. 655-660, 2009

[5] Kawawaki Y., Biased Risk Perception and Land Prices in the Disaster Area of the Great Hanshin-Awaji Earthquake, Japanese Journal of Real Estate Sciences 21(1), 2007

[6] Kawamura S., Relationship between Real Estate Transactions by Fukushima Refugees and Land Price Changes after The Great EastJapan Earthquake, Proceedings of the General Meeting of the Association of Japanese Geographers, 2013a(0), 100141, Session ID: 316, 2013

[7] Mori H., Taniguchi M., Actual conditions of real estate circulation and preferences for living places after earthquake-stricken areas, journal of Social Safety Science, No.24, 2014.11

[8] Saito M., An Approach to Influence on City Planning by Accepting Evacuees due to Nuclear Accident, 2018 Vol.53 Issue 3, pp.919-926

[9] Yamanashi Y., Ubaura M., A Study on Develop1nent Permission Trends in Affected Areas after the Great East Japan Earthquake, journal of the city planning institute of Japan, 52(3), pp1044-1050

[10] Hirota Y., Nuclear Power Plant Accident Due to the Great East Japan Earthquake and Appraisal of Real Estate, The Appraisal Journal Summer 2011 Vol.53, No.3 pp25-40、2011.07

[11] Gamble, H.B., and Downing R.H., "Effects of Nuclear Power Plants on Residential Property Values," Journal of Regional Science, 1982, 457-478.

[12] OECD Glossary of Statistical Terms, Organization for Economic Co-operation and Development, 
https://stats.oecd.org/glossary/detail.asp?ID=1 225, (10th June 2021)

[13] Shimada K., Yoshida T., Urban and Environmental Policy Assessment for Kyoto, Osaka and Kobe City by The Hedonic Price Method, Proceedings of Annual Meeting of Environmental Systems Research, Vol.40
PP.373-378, 2012

Copyright (C Int. J. of GEOMATE All rights reserved, including making copies unless permission is obtained from the copyright proprietors. 